\title{
El malestar del sujeto en la sociedad de consumo
}

Pablo Zanor ${ }^{1}$

Universidad Nacional de La Matanza

Tipo de trabajo: Ensayo

Material original autorizado para su publicación en el Journal de Ciencias Sociales, Revista Académica de la Facultad de Ciencias Sociales de la Universidad de Palermo.

Recibido: 2-12-2014

Aceptado: 12-1-2015

\section{Resumen:}

El ensayo señala la fractura entre la conciencia personal y la sociedad como la causa del desencanto del sujeto con él mismo y con lo institucional. La sociedad moderna, preocupada por la producción y el consumo, habría olvidado precisamente a la persona misma y el tratamiento de temas fundamentales tales como la relación varón y mujer, la educación, el sufrimiento y la muerte, la justicia y la culpa y sobre todo el bien y el mal. El ensayo llama la atención también sobre la necesidad de las relaciones sociales, sobre todo las llamadas relaciones primarias, que permiten al sujeto encontrar un sentido a la vida. Termina proponiendo una educación que gire en torno a la elaboración de una adecuada ciencia moral y pedagógica como solución a la falta de sentido.

Palabras clave: Felicidad, Sujeto y sociedad, Sentido, Relaciones sociales.

\section{Abstract:}

The essay deals with the fracture between the personal consciousness and the society as the consequence of the disenchantment of the subject with himself and the institutional. The modern society focused on production and consumption has apparently neglected the person itself as well as essential issues such as the relationship between men and women, education, suffering and

\footnotetext{
${ }^{1}$ Doctor en Teología. Especialidad Matrimonio y Familia, Pontificia Università Lateranense, Italia. Profesor Adjunto Regular Departamento de Humanidades y Ciencias Sociales de la Universidad Nacional de La Matanza, Argentina. pzanor@gmail.com
} 
death, justice and guilt and above all the good and the evil. The essay also highlights the need of establishing social relationships, mainly the so called primary ones, which allow the subject to find a sense to life. It ends proposing an education based on the construction of an adequate moral and pedagogical consciousness as an answer to the lack of sense.

Keywords: Happiness, Subject and society, sense, social relationships.

\section{Introducción}

Es un hecho que el avance tecnológico y científico, en casi todas las áreas de la vida humana, ha tenido un crecimiento exponencial en los últimos años. Esta situación no pareciera haber sido acompañada de un aumento de lo que tradicionalmente se llamaba felicidad, realización personal o calidad de vida.

En efecto, "no solo la felicidad de los países no se ha incrementado, sino que si observamos las tasas de prevalencia de algunos trastornos psicológicos (v.g. depresión) estos han aumentado su frecuencia de forma considerable." (Castro Solano - Tonon, 2013, p. 220)

El modelo que prevalece es asociar la felicidad con la acumulación de placer y el incremento de emociones positivas a partir de un sinfín de bienes que se pueden adquirir con el dinero. (Castro Solano - Tonon, 2013, p. 220)

Pero el modelo no pareciera ser correcto. Los resultados en torno a la calidad de vida en países que experimentan un aumento en su PBI registran una disminución en su calidad de vida. Por ello es que los investigadores en el área de la calidad de vida concluyen que no es adecuado medirla solo en función del bienestar material sino que debe ser complementada con mediciones subjetivas. Prueba de ello es que el nivel de satisfacción podría decrecer aunque aumentara el PBI de un país. (Tonon, 2008, p. 1)

\section{Las causas del disgusto y algunas de sus consecuencias}

El disgusto obedece fundamentalmente a un quiebre entre lo que el sujeto aporta a la vida social y los escasos recursos simbólicos que en ella encuentra al momento de configurar su propia identidad. Se postula que el individuo se puede construir en su singular identidad al margen de cualquier relación social. Como consecuencia, las relaciones sociales son pensadas solo como 
relaciones convencionales, establecidas a través de libres convenciones entre particulares. De aquí el contrato social. Es el optimismo liberal de pensar que el sujeto pueda alcanzar su propia identidad autónomamente, es decir, al margen de la cultura, de la sociedad, de la fe y de las costumbres. Pero si bien esto pareció posible en el siglo pasado, aparece hoy claramente en crisis. En otras palabras: se trabaja mucho e incluso, en algunos casos, se puede ganar mucho dinero, pero no se logra integrar lo realizado en sociedad dentro de la construcción de la propia subjetividad. Como consecuencia, la persona se siente mal, vive mal, en tensión y se tiene finalmente la percepción de que lo institucional juega un papel contrario a la persona. No por casualidad se habla de una crisis de las instituciones por una parte al mismo tiempo que se critica todo lo institucionalmente establecido.

Este estado de situación, es decir, pensar el individuo separado de la sociedad, obedece a una serie múltiple de causas. En primer lugar, la división del trabajo y la forma mercantil de la sociedad moderna sostenida por la forma contractual de intercambio, junto con un alejamiento pronunciado de la fe y la crisis de las ideologías. ${ }^{2}$

Por otra parte, el éxito de la ciencia y de la técnica en la época moderna comporta la suspensión por la pregunta sobre el sentido de todas las cosas. En efecto, ellas se limitan a medir espacios y tiempos de los fenómenos de la naturaleza, brindan una serie de medios pero no un fin que pueda integrar y unificar la vida del sujeto y darle también un sentido. Pero no solo se suspende la reflexión por el sentido de la vida sino también existe una desatención de temas fundamentales como ser la relación del varón con la mujer, la educación, el sufrimiento y la muerte, la justicia y la culpa, y sobre todo el bien y el mal. La remoción de estas cuestiones radicales de la vida conduce inevitablemente a estilos de vida nihilistas. Pero como de esos temas la vida cotidiana no puede prescindir, el hombre moderno busca compensar la ausencia de una tal sabiduría mediante el discurso de los valores (Angelini, 1991, p.59). El discurso de los valores, tan nombrados hoy, no es más que algo ocasional y tan solo ello: un discurso. Los valores de los que se hablan son los que están de moda, y si al tiempo es moda platicar de otros, los anteriores se descartan y se presentan los nuevos, los actuales. No podemos dejar de mencionar, por último, la tentativa kantiana de construir un sujeto autónomo de cualquier tipo de condicionamiento interno (las pasiones y los deseos) o externo.

De este conjunto de cosas y otras se seguiría, en primer lugar, la fractura del individuo moderno: la

${ }^{2}$ Tanto la fe como las ideologías presentaron la posibilidad de una cosmovisión donde el sujeto tenía la posibilidad de lograr y encontrar unidad y sentido a su existencia, lo que le permitía construir su identidad y de este modo disminuir su desencanto social. 
percepción que tiene la persona de sentirse internamente tironeada por una multiplicidad de lealtades incompatible entre sí, que en su ruidosa carencia de armonía, solo coinciden en excluir un fin que las integre. Esta situación llega a tales niveles de confusión, que se podría decir que en un sujeto cohabitan varias personas, sin que llegue a identificarse con ninguna de ellas.

Otra consecuencia es la trágica fractura entre la conciencia del sujeto moderno y la sociedad: la insuficiente experiencia que el sujeto hace en la vida social para descubrir y realizar sus aspiraciones más profundas, las que no resultan claras en su definición. O sea, prevalece una desorientación existencial y una fuerte confusión con respecto a la propia identidad. Esto concluye en el divorcio entre la conciencia del sujeto y la sociedad y el subsiguiente desencanto del mundo, es decir, la desilusión de un orden social capaz de ayudar a la construcción de la conciencia del individuo. La hipótesis que se establece es pensar que la persona se podría construir en su singular identidad más allá de cualquier relación social. En definitiva, se trata de pensar lo social como si la persona no existiese. Las relaciones sociales son vistas como relaciones convencionales y sancionadas a través del contrato social. La separación entre conciencia y vida social terminaría por situar al sujeto moderno frente a la sensación de que su prestación a la sociedad no encuentra una correspondencia en el horizonte de un sentido que le permita realizarse. Generalmente el sujeto expresa esta situación con frases tales como “... y por lo que me pagan...”. En realidad, el problema de fondo, más allá de lo que implica una justa retribución, no es el dinero en sí, sino la falta de sentido y la imposibilidad de integrar lo realizado en un proyecto personal. En síntesis, la persona no encuentra en la sociedad algún principio que dé unidad a todas las distintas actividades que realiza y de aquí el desengaño.

En este sentido, el estudio del profesor Ronald Anderson Human Suffering and Quality of Life: Conceptualizing Stories and Statistics, expuesto en el marco del Congreso Internacional sobre calidad de vida de la Universidad de Lomas de Zamora en 2013, verifica precisamente que cuando el sujeto encuentra un sentido experimenta mayores niveles de satisfacción que cuando éste falta, independientemente de que tenga o no cubiertas sus necesidades básicas.

Por último, un testigo de esta situación es la sobrevaloración del cuerpo en los tiempos modernos.

De hecho, parece claro que en la actualidad estamos viviendo en una época en la que el cuerpo y su significado sociocultural han tomado dimensiones inusitadas. La insistente transmisión por los más diversos y escurridizos medios de comunicación 
de imágenes con cuerpos esbeltos (en mujeres) o musculosos (en hombres) unidas a mensajes sobre felicidad, éxito, y (auto)estima, ha asentado en el inconsciente colectivo la idea de que un cuerpo "perfecto" es sinónimo de vida perfecta. Y más: que sin un buen cuerpo no puede llevarse una buena vida, o que a mejor cuerpo, mejor vida. (Pérez-Samaniego - Sánchez Gómez, 2001, p. 6)

En efecto, cuando se experimenta una falta de sentido, los aspectos más inmediatos de lo humano (como el cuerpo) alcanzan un lugar inusitado dentro de la propia vida. Y de esto es ejemplo toda la publicidad.

\section{Relaciones sociales e identidad del sujeto}

Las relaciones sociales, contrariamente a lo que se percibe, constituyen un aporte esencial en la construcción de la identidad del sujeto. Solo a través de ellas el individuo accede a su propia identidad.

La conformación de la propia identidad es sobre todo biográfica y en primer lugar ligada a las figuras paternas y maternas, que no son ciertamente infalibles. Más allá de la configuración biográfica de la conciencia, el proceso atraviesa las formas de la cultura del grupo social dentro del cual la persona singular y su familia viven. De estas formas la conciencia moral tiene absoluta necesidad y por su defecto el sujeto sufre. En este sentido la conciencia pasa a ser un problema político. (Angelini, 2006, p. 153s.)

Por lo expuesto es que el primer ámbito social en la construcción de la propia identidad lo aporta la familia. De allí la importancia crucial que ésta tiene. Los padres -lo quieran o no- son significativos para sus hijos. Esto trae ciertos inconvenientes para la visión moderna del sujeto. En primer lugar atentaría contra el principio de autonomía, entendida como la formulación de una libertad exenta de cualquier tipo de condicionamiento, como ya mencionamos. En segundo lugar, los padres hoy son también deudores de una sociedad que no los ayudó a encontrar un sentido y por ello la queja y el mal humor no dejan de ser el ambiente habitual en muchas familias. Esta situación a su vez no ayuda a las jóvenes generaciones a encontrar su camino, más bien alimenta el deseo de no querer crecer, con la consiguiente dilatación en el tiempo de la etapa adolescente. En efecto, si crecer significa, entre otras cosas, tomar decisiones que configuran un determinado modo de ser, la falta de recursos para lograrlo prolonga la búsqueda. 
La expresión más acabada de esta fractura entre persona y sociedad se manifiesta en la separación entre derecho y moral. Es decir, por un lado lo legal indicaría un comportamiento externo sin referencia a la identidad del sujeto. Aún más, el sujeto percibe la norma moral como una concesión de su libertad a favor de una mejor convivencia social pero que en el fondo no tiene nada que ver con su identidad. Por otro lado, lo moral queda absorbido en lo legal.

Por último, la crisis en las ideologías conlleva la amenaza de entender la política ya no como la consecución de la figura de la buena sociedad. Por ello es que hoy los políticos se parecen más a administradores de bienes y servicios que a sujetos que persiguen el bien de los ciudadanos. De hecho, los gobiernos se autodenominan correctamente como "administraciones" y todo conflicto busca su solución en la negociación.

Esta situación genera varios problemas a la persona. En primer lugar, y el más importante, es la incapacidad de querer, de tomar decisiones y en definitiva pone en riesgo su libertad ${ }^{3}$. En segundo lugar, la persona se siente tironeada por diversas situaciones que buscan comprometerlo y, por el otro, se genera una polaridad -o una rivalidad- entre el sujeto individual y la sociedad que termina en la sospecha sobre lo institucional por una parte y a una tensión desgarradora interior por otra.

Además, la sospecha hacia todo lo institucional hace que el sujeto se confronte y que no logre en ese ámbito resolverse.

Otra consecuencia se verifica en la desilusión a la hora de emprender un trabajo o de sostenerlo en el tiempo, como así también la dificultad para la toma de decisiones significativas.

De este modo el sujeto intenta realizar su propia identidad a través e incluso más allá de la pluralidad y de las disparatadas situaciones vitales dentro de las cuales actúa, a través de las fluctuaciones ingobernables de los estados de ánimo y, finalmente, a través de la dispersión de las mismas edades de la vida.

\section{El sujeto moderno y la forma experimental de vida}

Esta crisis del sujeto en la sociedad compleja se manifiesta también en las formas del comportamiento. Con esto se quiere señalar que el sujeto no actúa a partir de una persuasión o convicción que lo

${ }^{3}$ Cuando hablamos de libertad no nos referimos a la capacidad de elección o autodeterminación del sujeto sino a un estado de la persona misma en la que ella se encuentra conectada con sí misma, es decir, un estado que psicológicamente lo podríamos describir como de plenitud. 
encaminan hacia un determinado sentido sino que busca en el obrar convicciones para la propia vida. Su comportamiento asume la forma de un experimento, es decir, la persona actúa sin compromiso alguno y todo se transforma en un simple tentativo.

El modelo experimental aparece alimentado por las complejas formas de vida propias de la civilización de la abundancia. En efecto, la gran cantidad de posibilidades -dispares y cualitativamente tan distintas- se ofrecen muchas veces como una posibilidad para la libertad del sujeto, quien no goza de la competencia necesaria para poder realizarlas. De este modo el sujeto aparece como incapaz de realizar un discernimiento y una elección motivada.

Se termina asumiendo, como consecuencia, el rol de telespectador. Por ejemplo: hay cientos de "canales" (posibilidades) frente a los cuales es incapaz de elegir alguno y más bien se dejará elegir por alguno de ellos. La persona se presta a que el espectáculo lo convenza porque no posee criterios para seleccionar o elegir y ni siquiera suficiente información sobre los programas ofrecidos y mucho menos a qué hacen referencia o a su contenido.

La situación de telespectador asume, así, la fisonomía del consumo. Las posibilidades de multiplicar el consumo se desarrollan a través de la publicidad. Lo curioso de ésta es que no solo oferta un producto a través de la imagen sino también la imagen misma. La publicidad no ofrece un producto que el sujeto entienda como una suma en la realización de sus propios deseos definidos precedentemente: lo que ofrece es una atrayente posibilidad de vida, un sentido y, por lo tanto, una imagen de lo propiamente humano. La cualidad del consumidor (es decir, una persona despojada de un sentido) explica el éxito del consumo a partir de la publicidad. También da razones, una vez más, de la conducta experimental que el sujeto asume.

Esta circunstancia comporta notables inconvenientes. En primer lugar, y sobre todo, la sensación desagradable de perder los días de la vida. Lo más grave es que no se trata solo de una sensación sino de una pérdida real. De simples experimentos no se puede aprender nada. Para aprender de aquello que se hace es necesario tener una expectativa, un deseo, una ilusión determinada. El estilo experimental solo alimenta la conciencia inmadura del sujeto, la cual involuciona a formas únicamente emotivas e instintivas que no son ni claras para el propio sujeto ni lo hacen capaz de ser responsable frente a los demás. De este modo la cultura moderna aparece signada por una fuerte tendencia adolescente y consecuentemente narcisista. En efecto, el adolescente en todo lo que hace 
se busca a sí mismo, es autorreferencial, no se dona, solo a través del experimento el adolescente puede llegar a la conciencia de sí y a la realización de su identidad personal que en el momento presente le falta. Llega luego el momento de la decisión que es la que permite realizar la propia identidad. Pero para ello es necesario encontrar puntos fijos de referencia. Este es precisamente otro problema en la sociedad moderna. No los hay o son inalcanzables, me refiero sobre todo a los ídolos deportivos que dominan gran parte del imaginario social. Esto quiere decir que no se puede alcanzar la realización en la soledad mediante solo experimentos. Como se puede observar, hay un serio problema en torno a lo educativo.

\section{Conclusión}

El remedio a tal situación no parece que se pueda esperar de un improbable giro radical de la tendencia de la sociedad actual. Debe ser buscado a través de una iniciativa deliberada y volcada a la formación de la conciencia, es decir, atenta a la identidad original de cada sujeto. Esto implica la urgente necesidad de elaborar una ciencia moral y una ciencia pedagógica, capaces de promover los recursos necesarios para la realización de una educación moral, entendida como la promoción del sujeto en su originalidad. (Angelini, 1999, p. 52)

Con relación a la formación moral, las condiciones que permitirían garantizar la forma de la conciencia individual suponen formas que le permitan al sujeto proveerse de una regla interna que le permita alcanzar su propia libertad. En otros términos, se necesita de una conciencia moral. Una tal conciencia moral es posible, por otra parte, únicamente sobre la base de un ethos, que solamente el consenso social puede garantizar. En efecto, la conciencia de cada uno posee una deuda radical con relación a los otros y a la forma moral que la vida adquiere. (Angelini, 2008, p. 199)

La ciencia pedagógica debería centrarse en el sujeto y, en este sentido, algunos elementos que debería tener y que parecieran no poder faltar son: el reconocimiento de la originalidad de cada persona, la creación de ambientes donde el sujeto pueda experimentar, crear e investigar las distintas áreas del universo, el respeto de los procesos de cada uno y de las características propias de cada edad evolutiva, modelos de referencia accesibles, relatos y ejemplos biográficos, una autoridad entendida como servicio a la persona en su singularidad, entre otros.

Esto último supondría plantear el proceso de enseñanza-aprendizaje a partir de las necesidades e intereses del alumno, no agobiar al sujeto con expectativas y, por otra parte, observarlo más para 
entenderlo mejor y poder ayudarlo adecuadamente. Esto es: una educación más personalizada. Como consecuencia, se debería entender al docente no como el centro del proceso de enseñanza - aprendizaje sino como un facilitador y acompañante del alumno y constructor junto con él del conocimiento. Por tanto, proporcionar un medio que estimule el interés por el avance en el aprendizaje de los alumnos. Esto es, entender el ámbito educativo como un banco de experiencias en donde el sujeto pueda reconocerse a sí mismo y poder ir esbozando su propia personalidad. De este modo se estimularía la creatividad, es decir, la capacidad de generar ideas originales, que le permitirán al sujeto una mejor adaptación y afrontar un entorno en constante cambio, pero por sobre todo poder pensarse a sí mismo. Por último, insertar el proceso educativo dentro de un relato, como ya señalamos, lo que le permite al sujeto verificar la propia identidad, sentirse parte de algo que va más allá de sí mismo y de lo que hace concretamente y, finalmente, poseer un marco de referencia que le permita desarrollar sus propias habilidades y desplegar su propia identidad. 


\section{Referencias Bibliográficas:}

Anderson, R. (2014). Human Suffering and Quality of Life: Conceptualizing Stories and Statistics en SpringerBriefs in Well-Being and Quality of Life Research, (Vol, 9, pp. 105). Netherlands: Springer.

Angelini, G. (1991). I/ Figlio. Una benedizione, un compito, Milano: Vita e Pensiero.

Angelini, G. (1999). Teologia Morale Fondamentale, Milano: Glosa.

Angelini, G. (2006). Eros e Agape. Oltre l'alternativa, Milano: Glosa.

Angelini, G. (2008). La testimonianza. Prima del dialogo e oltre, Milano: Centro Ambrosiano.

Castro Solano A - Tonon G. (2013). Naciones felices: Más allá del dinero, en ECOS, (Vol. 4, № 2, pp. 219-228). Rio de Janeiro: Editorial Universidade Federal Fluminense.

Pérez-Samaniego - Sánchez Gómez, (marzo de 2001). Las concepciones del cuerpo y su influencia en el currículum de la Educación Física. Capturado el 18 de enero de 2010 en http://www.efdeportes. com/efd33a/cuerpo.htm

Tonon, G. (2008). Los estudios sobre calidad de vida en la Aldea Global, en América Latina y en Argentina. Revisión conceptual. Mar del Plata: EUDEM

Zuanazzi, G. (1995). L'età ambigua, Brescia: La Scuola. 